\title{
CORONARY ARTERY BYPASS SURGERY WITH ARTERIAL GRAFTS IN FAMILIAL HYPERCHOLESTEROLEMIA
}

Michio Kawasuji, MD

Naoki Sakakibara, MD

Susumu Fujii, MD

Tamotsu Yasuda, MD

Yoh Watanabe, MD
Objective: Familial hypercholesterolemia is a dominantly inherited disorder caused by mutations at the locus for the low-density lipoprotein receptor and is frequently associated with premature coronary artery disease. This study was performed to determine whether arterial grafting was associated with long-term benefits for patients with familial hypercholesterolemia.

Methods: During the past 18 years, 101 patients with heterozygous familial hypercholesterolemia underwent primary coronary artery bypass grafting, with one hospital death. Group 1 patients $(n=31)$ received only saphenous vein grafts. Group $2 \mathrm{~A}$ patients $(n=47)$ received one internal thoracic artery graft and supplemental vein grafts, and group $2 \mathrm{~B}$ patients $(\mathrm{n}=23)$ had multiple arterial grafts. After operation, all patients received diet therapy and intensive cholesterol-lowering drug therapy. Thirteen patients received lowdensity lipoprotein apheresis.

Results: During a mean follow-up period of 95 months, 8 patients died, 9 underwent reoperation, and 12 received catheter intervention. The overall survival was $82 \%$ (95\% confidence limits, 65\%-97\%) at 18 years after operation. The survival in group 2 was higher than that found in group $1(P=$ $.01)$. The overall freedom from major cardiac events (myocardial infarction, cardiac death, reoperation, and catheter intervention) was 57\% (95\% confidence limits, $40 \%-74 \%$ ) at 16 years after operation. The freedom from reoperation in group 2 was higher than that found in group $1(P=.03)$. There was no difference in the survival or freedom from major cardiac events between groups $2 \mathrm{~A}$ and $2 \mathrm{~B}$.

Conclusion: Arterial grafting improved the long-term freedom from reoperation in patients with familial hypercholesterolemia. Additional benefit of multiple arterial grafting could not be identified. (J Thorac Cardiovasc Surg 2000;119:1008-14)
$F^{i}$ amilial hypercholesterolemia $(\mathrm{FH})$ is a dominantly inherited disorder caused by mutations at the locus for the low-density lipoprotein receptor. ${ }^{1,2} \mathrm{FH}$ is characterized by severe hypercholesterolemia caused by increased levels of plasma low-density lipoprotein. FH is frequently associated with premature coronary artery

From the Department of Surgery (I), Kanazawa University School of Medicine, Kanazawa, Japan.

Received for publication July 8, 1999; revisions requested Sept 17, 1999; revisions received Nov 15, 1999; accepted for publication Dec 7, 1999.

Address for reprints: Michio Kawasuji, MD, Department of Surgery (I), Kanazawa University School of Medicine, Takaramachi 13-1, Kanazawa 920-8640, Japan (E-mail: kawasuji@med.kanazawa-u.ac.jp). Copyright $@ 2000$ by The American Association for Thoracic Surgery 0022-5223/2000 $\$ 12.00+0 \quad \mathbf{1 2 / 1 / 1 0 4 8 7 4}$

doi: $10.1067 / \mathrm{mtc} .2000 .104874$ disease in addition to the development of cutaneous and tendon xanthoma. ${ }^{1,3}$ Heterozygous $\mathrm{FH}$ is a relatively common disorder, occurring in approximately one of every 500 persons in Japan and in Western countries. Heterozygous FH causes coronary artery stenosis in the second decade of life, which progresses more rapidly than in the general population. The death rate from coronary artery disease among patients with heterozygous FH is several times higher than that found among the general population. ${ }^{4}$ Coronary artery bypass grafting $(\mathrm{CABG})$ has been performed to relieve myocardial ischemia and to reduce the morbidity and mortality of myocardial infarction in patients with $\mathrm{FH}^{5}$ The internal thoracic artery (ITA) is associated with a rate of longterm patency superior to that of a saphenous vein graft. The use of the ITA for the left anterior descending coronary artery has reduced the prevalence of late cardiac 
events and has improved the late survival after CABG. ${ }^{6,7}$ ITA grafting for lesions in the left anterior descending coronary artery has been advocated, and additional arterial grafts have been preferable to other coronary artery systems. ${ }^{8,9}$ However, the benefit of arterial grafts has not been clarified in patients with $\mathrm{FH}$ who have rapidly progressing coronary artery disease.

The purpose of this study was to report our 18-year experience with CABG in 101 patients with heterozygous FH and their long-term outcome and to determine whether arterial grafting was associated with survival benefits for patients with FH. The findings in extreme cases may have important implications for the medical and surgical treatment of patients with coronary artery disease.

\section{Patients and methods}

The subjects were 101 patients with heterozygous FH who underwent primary CABG between June 1980 and May 1999 at Kanazawa University Medical Center. The patient group included 75 men and 26 women who ranged in age from 32 to 77 years, with a mean age of 55 years. FH was diagnosed according to the following 2 criteria: primary hypercholesterolemia (above $230 \mathrm{mg} / \mathrm{dL}$ regardless of age group) with tendon xanthoma and primary hypercholesterolemia with or without tendon xanthoma in a first-degree relative of patients with $\mathrm{FH} .{ }^{4}$ All of the patients had heterozygous FH. The mean level of plasma cholesterol before introduction of cholesterollowering drug therapy was $326 \pm 62 \mathrm{mg} / \mathrm{dL}$; the low-density lipoprotein cholesterol level was $233 \pm 71 \mathrm{mg} / \mathrm{dL}$, high-density lipoprotein level $36 \pm 13 \mathrm{mg} / \mathrm{dL}$, and triglyceride level $164 \pm 91 \mathrm{mg} / \mathrm{dL}$. Thirty-four of the patients had hypertension, and 30 had diabetes mellitus. Two patients had 1-vessel disease, 19 patients had 2-vessel disease, 51 had 3-vessel disease, and 29 had left main coronary artery disease. The extent and severity of coronary stenotic changes were assessed by assigning scores to each of the 15 coronary artery segments, according to the classification of the American Heart Association Grading Committee. ${ }^{10}$ A normal coronary angiogram was graded 0 , stenosis of less than $25 \%$ was graded $1,25 \%$ to $49 \%$ stenosis was graded $2,50 \%$ to $74 \%$ was graded 3 , and $75 \%$ or more stenosis was graded 4 . The coronary stenosis index was defined as the sum of these scores. ${ }^{4}$ The severity of coronary stenosis was graded 0 when postoperative angiography indicated complete revascularization of the target coronary artery. The mean value of the coronary stenosis index before the operation was 19.8 (range, 8-36). Forty-three patients had a history of remote myocardial infarction confirmed by electrocardiographic changes, enzymatic changes, or both. Four patients had left ventricular aneurysms. Five patients had mild aortic valvular stenosis, and one had aortic valvular regurgitation. One patient had hypertrophic cardiomyopathy, and one had infective endocarditis of the tricuspid valve. The mean left ventricular ejection fraction was 0.61 (range, 0.18-0.85). Ten patients had abdominal aortic aneurysm, 14 had peripheral arterial disease, and 7 had a history of cerebrovascular disease. Ten patients had a family history of CABG.

The patients underwent primary $\mathrm{CABG}$ procedures with a total of 82 ITA grafts, 14 gastroepiploic artery grafts, and 162 saphenous vein grafts. The average number of grafts per patient was 2.6. The patients were divided into 3 groups according to the type of bypass graft. Thirty-one patients (group 1) received saphenous vein grafts to major coronary artery systems. Seventy patients (group 2) received arterial grafting with or without saphenous vein grafting; 47 of these patients (group 2A) underwent single arterial grafting, and 23 patients (group 2B) underwent double arterial grafting. Eleven patients received bilateral ITA grafts to the left anterior descending and circumflex coronary arteries, and 12 patients received both a left ITA graft to the left coronary artery system and a gastroepiploic artery graft to the right coronary artery system. Concomitantly, 4 patients underwent left ventricular aneurysmectomy, 1 received tricuspid valvuloplasty, and 1 had graft replacement of the abdominal aortic aneurysm. The clinical characteristics of the 3 groups are shown in Table I. Group 2B included a higher percentage of young male patients than the other groups. The patients of group 1 received fewer grafts than those of group 2 .

After the operation, all patients received diet therapy and cholesterol-lowering drug therapy with pravastatin, probucol, or cholestyramine (INN: colestyramine) to reduce their cholesterol level to less than $180 \mathrm{mg} / \mathrm{dL}$ and their low-density lipoprotein cholesterol level to less than $130 \mathrm{mg} / \mathrm{dL}$ (Table II). Thirteen patients who were resistant to drug therapies received treatment with low-density lipoprotein apheresis with a dextran-sulfate cellulose column. ${ }^{11}$ These included 2 patients of group 1 and 11 patients of group 2. The average duration of follow-up after operation was 95 months (range, 3-226 months; $136 \pm 61$ months for group 1 and $75 \pm 40$ months for group 2). Clinical information of survival and subsequent events was obtained every year by telephone interview with patients or their physicians. Data are expressed as means \pm SD unless otherwise specified. Variables were analyzed by using the Student $t$ test, analysis of variance, and the $\chi^{2}$ test to detect significant $(P<.05)$ differences between the measured variables. The survival and freedom from major cardiac events (myocardial infarction, cardiac death, reoperation, and catheter intervention) after operation were calculated by the Kaplan-Meier method and were analyzed by the Mantel-Cox log-rank test to detect significant differences.

\section{Results}

One hundred (99\%) of the 101 patients successfully underwent primary CABG. One patient died of graftversus-host disease resulting from a blood transfusion. Coronary angiography was performed within 2 months after operation in 96 patients. The overall graft patency after operation was $94 \%$ (100\% for all 82 ITA grafts 
Table I. Clinical characteristics of the 3 groups

\begin{tabular}{|c|c|c|c|c|}
\hline Factor & Group $1(n=31)$ & Group $2 A(n=47)$ & Group $2 B(n=23)$ & $\mathrm{P}$ value \\
\hline Age (y) & $56 \pm 9$ & $57 \pm 10$ & $49 \pm 10$ & .002 \\
\hline $\operatorname{Sex}(M / F)$ & $21 / 10$ & $32 / 15$ & $22 / 1$ & .003 \\
\hline Total cholesterol (mg/dL) & $323 \pm 62$ & $320 \pm 58$ & $340 \pm 71$ & .6 \\
\hline LDL cholesterol (mg/dL) & $231 \pm 67$ & $220 \pm 66$ & $273 \pm 83$ & .2 \\
\hline Coronary artery disease & & & & .3 \\
\hline One vessel & $1(3 \%)$ & $1(2 \%)$ & 0 & \\
\hline Two vessel & $4(13 \%)$ & $7(15 \%)$ & $8(35 \%)$ & \\
\hline Three vessel & $14(45 \%)$ & $27(57 \%)$ & $10(43 \%)$ & \\
\hline Left main trunk & $12(39 \%)$ & $12(26 \%)$ & $5(22 \%)$ & \\
\hline Coronary stenosis index & $20.3 \pm 6.1$ & $20.1 \pm 6.4$ & $18.2 \pm 4.4$ & .5 \\
\hline Left ventricular EF & $0.58 \pm 0.18$ & $0.61 \pm 0.14$ & $0.65 \pm 0.11$ & .3 \\
\hline Prior MI & $18(58 \%)$ & $19(40 \%)$ & $6(26 \%)$ & .06 \\
\hline Grafts per patient & $2.2 \pm 0.7$ & $2.7 \pm 0.7$ & $2.7 \pm 0.6$ & .003 \\
\hline
\end{tabular}

$L D L$, Low-density lipoprotein; $E F$, ejection fraction; $M I$, myocardial infarction.

Table II. Changes in plasma lipids and coronary stenosis index after cholesterol-lowering therapy and CABG

\begin{tabular}{lcccc}
\hline Factors & Before treatment & After treatment & Change & P value \\
\hline Total cholesterol (mg/dL) & $326 \pm 62$ & $199 \pm 36$ & $-39 \% \pm 14 \%$ & $<.001$ \\
LDL cholesterol (mg/dL) & $233 \pm 71$ & $133 \pm 34$ & $-43 \% \pm 20 \%$ & $<.001$ \\
HDL cholesterol (mg/dL) & $36 \pm 13$ & $32 \pm 12$ & $-8 \% \pm 34 \%$ & .06 \\
Triglyceride (mg/dL) & $163 \pm 91$ & $115 \pm 51$ & $-29 \% \pm 26 \%$ & $<.001$ \\
Coronary stenosis index & $19.8 \pm 5.9$ & $6.5 \pm 4.2$ & $-67 \% \pm 18 \%$ & $<.001$ \\
\hline
\end{tabular}

$L D L$, Low-density lipoprotein; $H D L$, high-density lipoprotein.

Table III. Changes in plasma lipids and coronary stenosis index in 13 patients with FH who underwent CABG and low-density lipoprotein apheresis

\begin{tabular}{|c|c|c|c|c|}
\hline Factors & Before treatment & After treatment & Change & $\mathrm{P}$ value \\
\hline Total cholesterol $(\mathrm{mg} / \mathrm{dL})$ & $378 \pm 64$ & $170 \pm 26$ & $-55 \% \pm 10 \%$ & $<.001$ \\
\hline LDL cholesterol (mg/dL) & $285 \pm 68$ & $113 \pm 37$ & $-62 \% \pm 10 \%$ & $<.001$ \\
\hline HDL cholesterol (mg/dL) & $35 \pm 11$ & $34 \pm 9$ & $-6 \% \pm 23 \%$ & .1 \\
\hline Triglyceride (mg/dL) & $167 \pm 93$ & $93 \pm 47$ & $-38 \% \pm 27 \%$ & .01 \\
\hline Coronary stenosis index & $24.4 \pm 5.7$ & $8.3 \pm 4.5$ & $-67 \% \pm 15 \%$ & $<.001$ \\
\hline
\end{tabular}

$L D L$, Low-density lipoprotein; $H D L$, high-density lipoprotein.

and 12 of the gastroepiploic arteries and $91 \%$ for the 158 saphenous vein grafts). The coronary stenosis index was reduced from $19.8 \pm 5.9$ to $6.5 \pm 4.2(P<$ .001) after the operation. The mean level of plasma cholesterol after intensive cholesterol-lowering therapy was $199 \pm 36 \mathrm{mg} / \mathrm{dL}(P<.001$ compared with levels before treatment); low-density lipoprotein cholesterol level was $133 \pm 34 \mathrm{mg} / \mathrm{dL}(P<.001)$, high-density lipoprotein level $32 \pm 11 \mathrm{mg} / \mathrm{dL}(P=.06)$, and triglyceride level $115 \pm 57 \mathrm{mg} / \mathrm{dL}(P<.001$; Table II $)$. Treatment with low-density lipoprotein apheresis significantly reduced the levels of total cholesterol, lowdensity lipoprotein cholesterol, and triglyceride (Table III). The levels of total cholesterol $(P<.001)$, low-den- sity lipoprotein cholesterol $(P=.03)$, and triglyceride $(P=.04)$ after treatment with lipoprotein apheresis were significantly lower than those for patients who did not receive treatment.

During the follow-up period, 8 patients died (7 of cancer and 1 of sudden death). Angina recurred in 25 patients, 2 of whom had a nonfatal myocardial infarction. The cause of the anginal recurrence was vein graft atherosclerosis in 15 patients, arterial graft failure in 3 patients, progression in native coronary stenosis in 6 patients, and unknown cause in 1 patient. For 24 patients who underwent coronary angiography because of recurrent angina, the patency was $87 \%$ for 15 ITA grafts, $67 \%$ for 3 gastroepiploic artery grafts, 

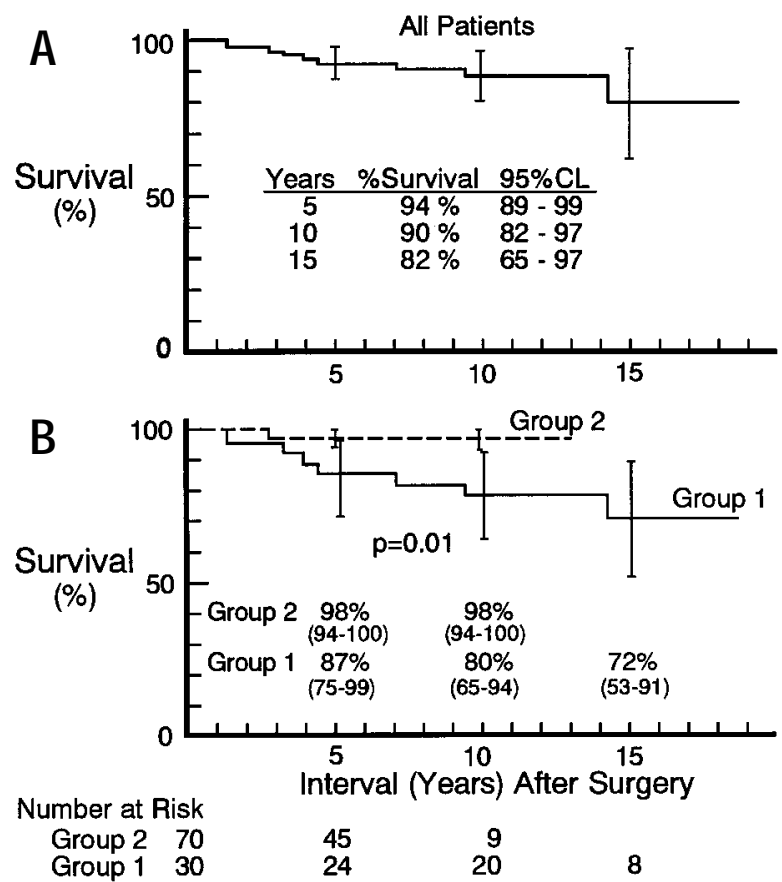

Fig 1. Long-term survival of patients with $\mathrm{FH}$ who underwent CABG. A, All patients; B, patients of group 1 and group 2 . The survival in group 2 was significantly $(P=.01)$ higher than that found in group 1 . The number of patients at risk at selected follow-up intervals is listed beneath panel B. Vertical bars show 95\% confidence limits for the survival estimates.

and $35 \%$ for 37 saphenous vein grafts. Postoperative cholesterol levels $(202 \pm 51 \mathrm{mg} / \mathrm{dL})$ for patients who had late cardiac events were not different from those $(199 \pm 30 \mathrm{mg} / \mathrm{dL})$ for patients who did not $(P=.7)$. Nine patients underwent reoperation because of vein graft atherosclerosis at an average of 8 years (range, 510 years) after the initial operation. These included 8 patients of group 1 and 1 patient of group 2. They underwent reoperation with 1 or 2 arterial grafts, and all survived reoperation. Twelve patients underwent percutaneous transluminal coronary angioplasty at an average of 4 years (range, 0.5-12 years) after the operation. These included 4 patients of group 1 and 8 patients of group 2. Four patients underwent graft replacement of the abdominal aortic aneurysm. Of the 13 patients who had been treated with lipoprotein apheresis, 3 underwent percutaneous coronary angioplasty, but none received reoperation.

The overall survival was $94 \%$ (95\% confidence limits [CL], 89\%-99\%) at 5 years after the initial operation, $90 \%$ (95\% CL, 82\%-97\%) at 10 years, and $82 \%$ (95\% CL, 65\%-97\%) at 18 years (Fig 1). There were 7 late deaths in group 1 and 1 late death in group 2 . The
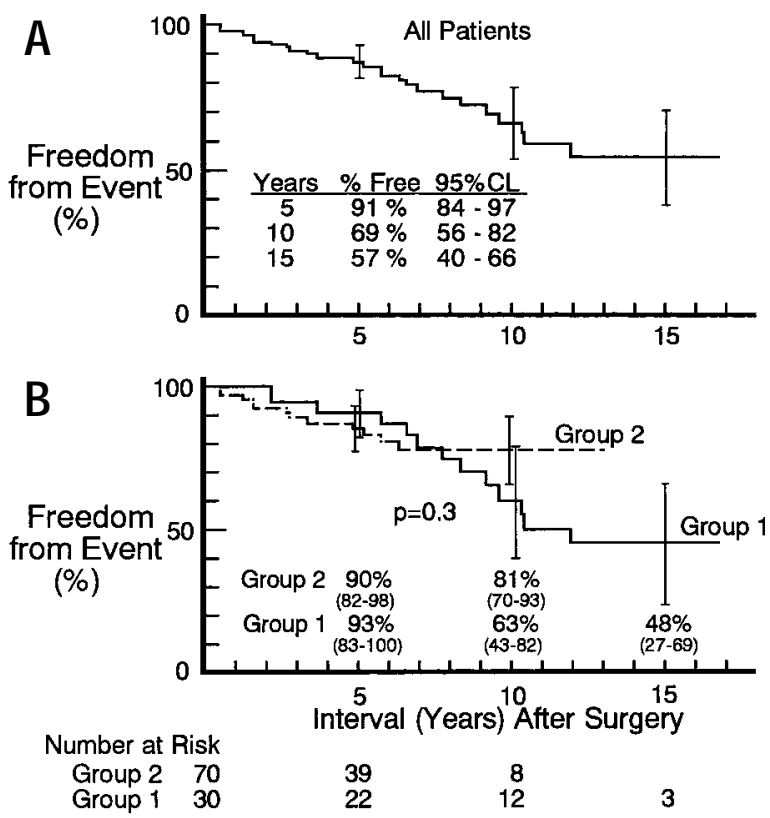

Fig 2. Freedom from major cardiac events of patients with FH who underwent CABG. A, All patients; B, patients of groups 1 and 2. There was no difference in the freedom from major cardiac events among the groups.

survival in group 2 was significantly higher than that found in group $1(P=.01)$. The overall freedom from major cardiac events (myocardial infarction, cardiac death, reoperation, and catheter intervention) was $91 \%$ (95\% CL, 84\%-97\%) at 5 years after the operation, $69 \%(95 \% \mathrm{CL}, 56 \%-82 \%)$ at 10 years, and $60 \%(95 \%$ $\mathrm{CL}, 40 \%-74 \%$ ) at 16 years (Fig 2). There were no differences in the freedom from major cardiac events between group 1 and group $2(P=.3)$ or between group $2 \mathrm{~A}$ and group $2 \mathrm{~B}(P=.2)$. There was a tendency toward a higher freedom from major cardiac events in group 2 than in group 1 eight years after operation. The overall freedom from reoperation was $84 \%$ (95\% CL, $72 \%$ $95 \%$ ) at 10 years after the initial operation and $76 \%$ (95\% CL, 62\%-91\%) at 16 years (Fig 3). The freedom from reoperation in group 1 was significantly lower than that found in group $2(P=.03)$.

\section{Discussion}

This study compared long-term survival and cardiac events between saphenous vein grafting and arterial grafting with supplemental vein grafts in patients with FH. The long-term freedom from reoperation was significantly higher in the arterial grafting group than that found in the vein grafting group, although the inci- 


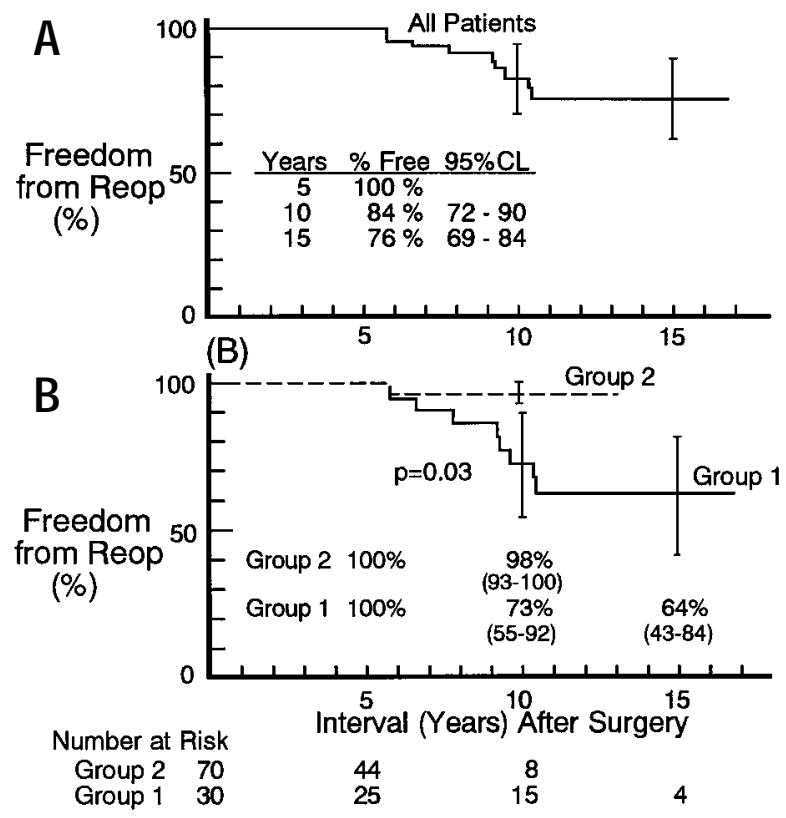

Fig 3. Freedom from reoperation (Reop) in patients with $\mathrm{FH}$ who underwent CABG. A, All patients; B, patients of group 1 and group 2. The freedom from reoperation in group 2 was significantly higher than that found in group 1 .

dence of major cardiac events could not show significant difference between the 2 groups.

A high plasma level of low-density lipoprotein cholesterol is an independent risk factor for coronary artery disease. ${ }^{3}$ Nonlipid coronary risk factors, such as hypertension, diabetes, cigarette smoking, and obesity, appear to be overridden by the more powerful risk factor of hereditary hypercholesterolemia. Patients with heterozygous FH constitute a homogeneous group of patients and are an excellent model for evaluating longterm outcomes after medical and surgical treatment of coronary artery disease. Intensive, lipid-lowering drug therapy reduced the frequency of progression of coronary lesions, increased the frequency of regression, and reduced the incidence of cardiovascular events in men with coronary artery disease and high levels of lowdensity lipoprotein cholesterol. ${ }^{12}$ In the Scandinavian Simvastatin Survival Study of a large number of patients with coronary heart disease, simvastatin significantly reduced the incidence of coronary events. ${ }^{13}$ The lower the plasma cholesterol levels, the greater the likelihood that coronary artery disease can be prevented or delayed. ${ }^{14}$ Intensive combination cholesterol-lowering drug therapy has been advocated as an effective therapy for patients with heterozygous FH. ${ }^{15}$ Low-density lipoprotein apheresis with a dextran-sulfate cellulose column is an intensive cholesterol-lowering therapy that is highly effective and selective in lowering lowdensity lipoprotein levels while leaving high-density lipoprotein levels unchanged. ${ }^{11}$ A long-term (mean interval of 6 years) study of patients with $\mathrm{FH}$ receiving low-density lipoprotein apheresis demonstrated that this therapy significantly decreased coronary events compared with drug therapy. ${ }^{11}$ It has been recognized that $\mathrm{CABG}$ improves the long-term survival in patients with FH. ${ }^{5,16}$ The issue is whether cholesterol-lowering therapy is similarly effective for long-term outcomes after CABG in patients with $\mathrm{FH}$. In a randomized trial of the Cholesterol Lowering Atherosclerosis Study over 4 years, combined colestipol-niacin therapy significantly decreased new lesions in native coronary arteries and vein bypass grafts but did not reduce the progression of vein graft lesions. ${ }^{17} \mathrm{~A}$ randomized study is ethically impossible in patients with $\mathrm{FH}$ after the evidence of effectiveness in secondary prevention studies. The present study could not demonstrate the influence of cholesterol levels on late cardiac events. However, 13 patients who received lipoprotein apheresis showed much lower cholesterol levels than the patients who did not, and 3 of them underwent catheter intervention, although none underwent reoperation. Further study may reveal the effectiveness of intensive cholesterollowering therapies for improving long-term results in surgical patients with $\mathrm{FH}$.

The other important issue is whether arterial grafting contributes to superior results and whether multiple arterial grafting provide additional benefits in patients with FH. Loop and colleagues ${ }^{6}$ have demonstrated a better late cardiac event-free survival after ITA grafting to the left anterior descending coronary artery compared with saphenous vein grafting. Galbut and colleagues ${ }^{8}$ reported superior results of bilateral ITA grafting to single ITA grafting. We have preferably used arterial grafts in our patients with FH over a 13-year period. Despite the high prevalence of extracoronary atherosclerotic lesions in patients with $\mathrm{FH}$, the ITA and the gastroepiploic artery showed no histologic differences from those in patients without FH. ${ }^{16}$ In the present study there were 8 late deaths, but only 1 of them was a cardiac death. Therefore we could not develop any conclusions regarding difference in late cardiac death between the groups. The present study showed that for patients with $\mathrm{FH}$, the use of a single ITA graft significantly increased the long-term freedom from reoperation. The effect of single ITA grafting was so powerful that multiple arterial grafting did not demonstrate any additional bene- 
fits with regard to long-term results in patients with FH. Comparing single and double ITAs by means of multivariate analysis, Naunheim and colleagues ${ }^{18}$ reported that double ITA grafting was not protective over a 15-year period with regard to survival. Sergeant and colleagues ${ }^{19}$ examined whether extensive arterial grafting beyond a single graft reduced the prevalence and consequences of myocardial infarction after CABG in a large series of 9600 patients. Multivariable analysis showed that arterial grafting lowered the prevalence of periprocedural, intermediate term, and late infarction. Although arterial grafting improved the 10-year survival, no additional benefit or cost of extensive arterial grafting was identified. Lytle and colleagues ${ }^{20}$ conducted a long-term (mean follow-up interval of 10 years) study of patients undergoing CABG who received either single (8123 patients) or bilateral ITA grafts (2001 patients). Patients who received 2 ITA grafts had significantly decreased risks of death, reoperation, and percutaneous transluminal coronary angioplasty. Patients with FH in the present study were relatively young, with a mean age of 55 years. In addition, coronary atherosclerosis in patients with FH progresses more rapidly than that in the general population. We think that intensive cholesterollowering therapies are mandatory for patients with $\mathrm{FH}$, even in the case of total arterial grafting. Further follow-up is warranted to determine more accurately whether multiple arterial grafting is preferable to single arterial grafting in patients with FH.

In conclusion, in patients with heterozygous FH, ITA grafting increased the long-term freedom from reoperation compared with saphenous vein grafting. No additional benefits of multiple arterial grafting could be identified.

\section{REFERENCES}

1. Goldstein JL, Brown MS, Hobbs HH. Familial hypercholesterolemia. In: Scriver CR, Beaudet AL, Sly WS, Valle D, editors. The metabolic and molecular bases of inherited disease. 7 th ed. New York: McGraw-Hill; 1995. p. 1981-2030.

2. Hobbs HH, Brown MS, Goldstein JL. Molecular genetics of the LDL receptor gene in familial hypercholesterolemia. Hum Mutat 1992;1:1445-66.

3. Mabuchi H, Koizumi J, Schimizu M, Takeda R, Hokuriku FH, CHD Study Group. Development of coronary heart disease in familial hypercholesterolemia. Circulation 1989;79:225-32.

4. Mabuchi H, Miyamoto S, Ueda K, et al. Cause of death in patients with familial hypercholesterolemia. Atherosclerosis 1986;61:1-6.

5. Kawasuji M, Sakakibara N, Takemura H, Matsumoto Y, Mabuchi $\mathrm{H}$, Watanabe $\mathrm{Y}$. Coronary artery bypass grafting in familial hypercholesterolemia. J Thorac Cardiovasc Surg 1995;109:364-9.

6. Loop FD, Lytle BW, Cosgrove DM, et al. Influence of the internal-mammary-artery graft on 10-year survival and other cardiac events. N Engl J Med 1986;314:1-6.
7. Tector AJ, Schmahl TM, Canino VR. The internal mammary artery graft: the best choice for bypass of the diseased left anterior descending coronary artery. Circulation 1983;68(Suppl):II214-7.

8. Galbut DL, Traad EA, Dorman MJ, et al. Seventeen-year experience with bilateral internal mammary artery grafts. Ann Thorac Surg 1990;49:195-201.

9. Grandjean JG, Boonstra PW, Heijer PD, Ebels T. Arterial revascularization with the right gastroepiploic artery and internal mammary arteries in 300 patients. J Thorac Cardiovasc Surg 1994;107:1309-16.

10. American Heart Association Committee Report: a reporting system on patients evaluated for coronary artery disease. Circulation 1975;51:7-40.

11. Mabuchi H, Koizumi J, Shimizu M, et al. Long-term efficacy of low-density lipoprotein apheresis on coronary heart disease in familial hypercholesterolemia. Am J Cardiol 1998;82:1489-95.

12. Brown G, Albers JJ, Fischer LD, et al. Regression of coronary artery disease as a result of intensive lipid-lowering therapy in men with high levels of apolipoprotein B. N Engl J Med 1990; 323:1289-98.

13. The Scandinavian Simvastatin Survival Study Group. Randomized trial of cholesterol lowering in 4444 patients with coronary heart disease: the Scandinavian Simvastatin Survival Study (4S). Lancet 1994;344:1383-9.

14. Stamler J, Wentworth D, Neaton J. Is the relationship between serum cholesterol and risk of death from CHD continuous and graded? JAMA 1986;256:2823-8.

15. Mabuchi H, Sakai T, Sakai Y, et al. Reduction of serum cholesterol in heterozygous familial hypercholesterolemia: additive effects on compactin and cholestyramine. N Engl J Med 1983; 308:609-13.

16. Tedoriya T, Kawasuji M, Sakakibara N, Ueyama K, Takemura $\mathrm{H}$, Watanabe Y. Coronary artery bypass surgery in patients with familial hypercholesterolemia. Jpn J Thorac Surg 1992;40:10959.

17. Cashin-Hemphill L, Mack WJ, Pogoda JM, Sanmarco ME, Azen SO, Blankenhorn DH. Beneficial effects of cholestipol-Niacin on coronary atherosclerosis. JAMA 1990;264:3013-7.

18. Nauheim KS, Barner HB, Fiore AC. Results of internal thoracic artery grafting over 15 years: single versus double grafts. 1992 update. Ann Thorac Surg 1992;53:716-8.

19. Sergeant PT, Blackstone EH, Meyns BP. Does arterial revascularization decrease the risk of infarction after coronary artery bypass grafting? Ann Thorac Surg 1998;66:1-11.

20. Lytle BW, Blackstone EH, Loop FD, et al. Two interanl thoracic artery grafts are better than one. J Thorac Cardiovasc Surg 1999; 117:855-72.

\section{Commentary}

We compliment Kawasuji and associates on their management and results over 18 years in 101 patients with familial hypercholesterolemia and severe coronary artery disease. Seventy patients received one or more arterial bypass grafts and 30 patients have saphenous vein grafts, for an average of 2.6 grafts per patient. Postoperatively, the patients' cholesterol levels 
were reduced to less than $180 \mathrm{mg} / \mathrm{dL}$ and their low-density lipoprotein cholesterol levels were reduced to less than $130 \mathrm{mg} / \mathrm{dL}$ with diet therapy and cholesterol-lowering drugs. The 13 patients who did not respond to drug therapy were treated with low-density lipoprotein apheresis.

This group of patients has premature coronary artery disease combined with high cholesterol levels and provides an excellent model to evaluate therapies to optimize results in high-risk patients. Postoperative management of patients can have an influence on the incidence of reoperation, and the importance of aggressive control of cholesterol levels should not be ignored. Aggressive lowering of low-density lipoprotein cholesterol levels was shown to decrease obstructive changes in saphenous vein grafts by $31 \%$ according to the National Heart, Lung, and Blood Institute study. ${ }^{1}$

The effect of maintaining low cholesterol levels in patients with complete arterial grafting is not known. Flaker and associates ${ }^{2}$ showed that a 3-hydroxy-3methylglutaryl coenzyme A reductase inhibitor reduced clinical events in revascularized postinfarction patients with average cholesterol levels. This fact, combined with the knowledge that control of cholesterol levels in the postoperative period halted the development of new lesions in native coronary arteries and bypass vein grafts but did not reduce the progression of vein graft lesions, has important implications. ${ }^{3}$ It seems that lowering of cholesterol levels is also beneficial in patients with total arterial grafting, at least in part because of slowing the development of new lesions. Intensive control of cholesterol levels in the postoperative period should be started immediately to prevent the progression of disease.

Even though this study did not reveal any significant benefit from multiple arterial grafting, one would suspect that the survival and outcomes would eventually be affected in view of the low patency in the saphenous vein grafts. The fact that the internal thoracic artery (ITA) has a higher patency than venous grafts supports the importance of arterial grafts. The benefits from total arterial revascularization will not be seen unless a very large number of patients are observed for an extended length of time. Lytle and associates ${ }^{4}$ reviewed more than 10,000 patients to show a benefit from bilateral ITA grafting.

What is not known is whether all arterial conduits are equivalent. Patency of the ITA, but not that of the radial artery, which differs in that it is a muscular artery, has proven to be superior. Further long-term studies into different forms of arterial revascularization will answer these questions.

This article demonstrates the importance of using arterial grafts combined with strict control of total and low-density lipoprotein cholesterol levels in patients undergoing coronary artery bypass grafting. Current available data on the beneficial effects of the new statin drugs only increase the importance of aggressive control of cholesterol levels in the postoperative patient. As surgeons, we must educate our patients and their family physicians on this vital issue. Striving for ways to halt progression of native and bypass graft disease may further decrease the incidence of coronary reoperations and other morbidities and enhance patient survival.

Alfred J. Tector, $M D$

Monica L. McDonald, MD Milwaukee, Wisconsin

\section{REFERENCES}

1. Campeau L, Hunninghake DB, Knatterud GS, et al. Aggressive cholesterol lowering delays saphenous vein graft atherosclerosis in women, the elderly, and patients with associated risk factors: NHLBI post coronary artery bypass graft clinical trial. PostCABG Trial Investigators. Circulation 1999;99:3241-7.

2. Flaker GC, Warnica JW, Sacks FM, et al. Pravastatin prevents clinical events in revascularized patients with average cholesterol concentrations. J Am Coll Cardiol 1999;34:106-12.

3. Cashin-Hemphill L, Mack WJ, Pogoda JM, Sanmarco ME, Azen SO, Blankenhorn DH. Beneficial effects of cholestipol-Niacin on coronary atherosclerosis. JAMA 1990;264:3013-7.

4. Lytle BW, Blackstone EH, Loop FD, et al. Two internal thoracic artery grafts are better than one. J Thorac Cardiovasc Surg 1999; 117:855-72.

12/1/105259

doi:10.1067/mtc.2000.105259 